\title{
The Impact of the Coronacrisis on KIBS Sector
}

\author{
Ian Miles \\ Emeritus Professor, Alliance Manchester Business Schoola; and Academic Supervisor, Laboratory for Economics of Innovation, \\ Centre for Science and Technology, Innovation and Information Policy, Institute for Statistical Studies and Economics of Knowledge \\ (ISSEK) $)^{\mathrm{b}}$, imiles@hse.ru
}

Veronika Belousova

Leading Research Fellow, ISSEK Unit for Intellectual Services Market Research ${ }^{\mathrm{b}}$, vbelousova@hse.ru

Nikolay Chichkanov

Research Fellow, ISSEK Unit for Intellectual Services Market Research; and Research Fellow, ISSEK Laboratory for Economics of Innovation ${ }^{\mathrm{b}}$, nchichkanov@hse.ru

\section{Zhaklin Krayushkina}

Research Assistant, ISSEK Unit for Intellectual Services Market Research ${ }^{\mathrm{b}}$, zkrayushkina@hse.ru

a University of Manchester, Oxford Rd, Manchester M13 9PL, UK

b National Research University Higher School of Economics, 11, Myasnitskaya str., Moscow 101000, Russian Federation

\begin{abstract}
$\mathrm{K}$ nowledge-Intensive Business Services (KIBS) are problem-solvers for other organizations. The coronacrisis affects KIBS directly, but also means that their clients are confronting new problems. How are KIBS addressing these two sets of challenges? This paper draws upon material available in the trade and industry press, on official reports and statistics, and the early academic studies addressing these themes. We find that KIBS have been active (alongside other organizations) in providing a substantial range of services aimed at helping their clients (and others) deal with the various contingencies thrown up by the crisis. Not least among these are the need to conform to shifting regulatory frameworks and requirements for

longer-term resilience. KIBS themselves have had to adapt their working practices considerably, to reduce face-to-face interaction with clients and within teams collaborating on projects. Adaptation is easier for those whose tasks are relatively standardized and codified, and it remains to be seen how far a shift to such activities - and away from the traditional office-based venues of activity - is retained, as firms recover from the crisis. KIBS are liable to play an important role in this recovery from the crisis and policymakers can mobilize their services. Some KIBS are liable to be critical for rendering economies more resilient in the face of future pandemics, and we argue that these firms are also important for confronting the mounting climate crisis.
\end{abstract}

Keywords: KIBS; coronavirus pandemics; coronacrisis; COVID-19; longer-term resilience
Citation: Miles I., Belousova V., Chichkanov N. Krayushkina Zh. (2021) The Impact of the Coronacrisis on KIBS Sector. Foresight and STI Governance, 15(1), 6-18. DOI: $10.17323 / 2500-2597.2021 .1 .6 .18$ 


\section{KIBS and Crises}

Knowledge-Intensive Business Services (KIBS) are critical components of modern economies, as has been argued in several essays in this journal and elsewhere. KIBS are private firms, applying expertise to the business problems of clients. Figure 1 provides an overview of the industrial sectors involved in traditional professional services (e.g., accountancy and legal services), technology and engineering-related services (including computer and information technology (IT) services, research and development (R\&D), and testing services), and services with more of a creative/cultural focus (advertising, design, etc). They have grown rapidly in modern economies and become integrated into many supply chains and business strategies. The future of KIBS is of obvious interest to all analysts of long-term change in economies, employment, and knowledge dynamics. This essay considers how their future is liable to be affected by the Coronacrisis. We refer here to:

- the complex of events surrounding the immediate effects of the pandemic associated with the SARSCOV2 virus and the disease it causes, COVID-19;

- the major social and economic interventions undertaken by governments around the world in attempts to control and/or manage the pandemic; and

- the substantial and potentially long-lasting effects of the lockdowns and other measures that have been introduced.

\section{Lessons from the Previous Crises}

The world of course has experienced pandemics before the current coronacrisis, but the current situation is very different from that of a century ago. While the coronacrisis is widely seen as being more likely to resemble the Great Depression of the 1920s and 1930s in terms of massive and long-lasting economic impacts, KIBS, in general, were very small parts of national economies at that time. The impact of the coronacrisis on KIBS is thus without precedent in the history of pandemics. We can examine KIBS' response to more endogenous economic crises. The most recent major global economic crisis, the Great Recession, was triggered by the financial crisis of 2007-2008 at a time when KIBS had developed to a scale roughly similar to that we see today. The general picture seems to be that the impact of the Great Recession (henceforth GR) on KIBS was abrupt but short-lived. Figures $2 \mathrm{a}$ and $2 \mathrm{~b}$ present trend data for the EU-15 economies. The growth or decline of employment and output in KIBS sectors and the whole economy is represented (each indicator is given the baseline of 100 in the year 2000).

Before the crisis, all KIBS employment grew more rapidly than the economy as a whole. With the onset of the crisis, employment decreases were relatively higher in several KIBS than in the whole economy (Advertising; Architecture and Engineering - hence A\&E). However, most KIBS sectors recovered to practically pre-crisis employment growth rates by early 2010 . Advertising, however, lacked the dynamism of other KIBS and if anything

\section{Figure 1. Main Categories and Statistical Classifications of KIBS}

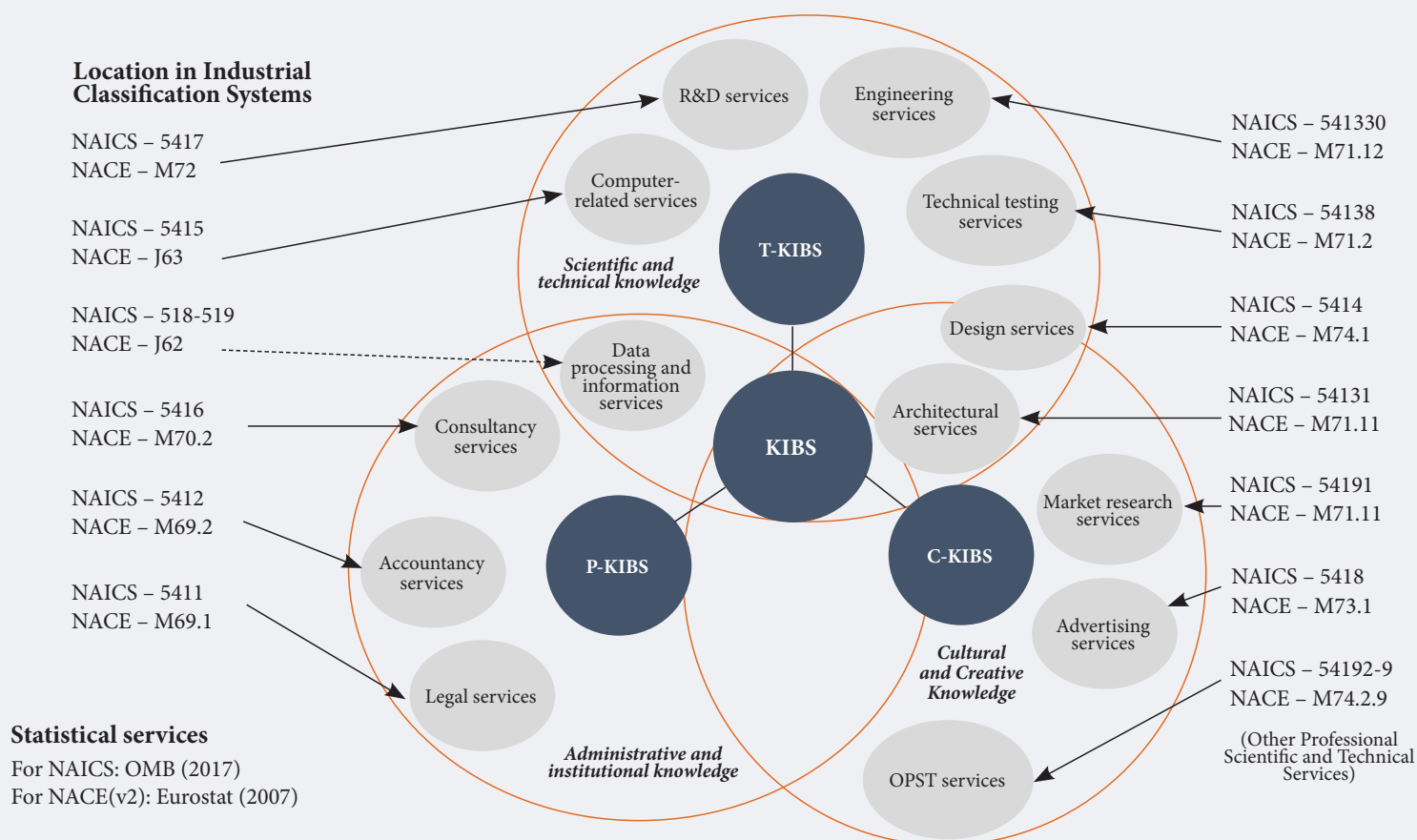

Note: The group of Data Processing and Information Services has been added to the standard list of KIBS since these are also mainly B2B services requiring considerable professional expertise. They are in any case often aggregated with Computer-related Services in published data presentations and downloads.

Source: authors. 
2a. Employment (Persons employed)

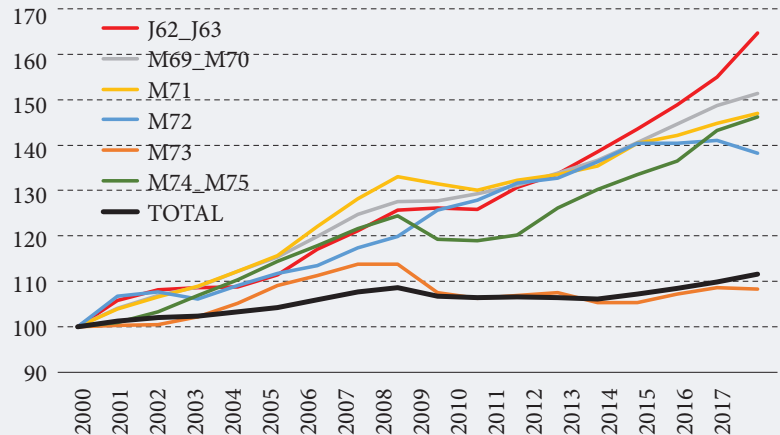

2b. Output (Current prices)

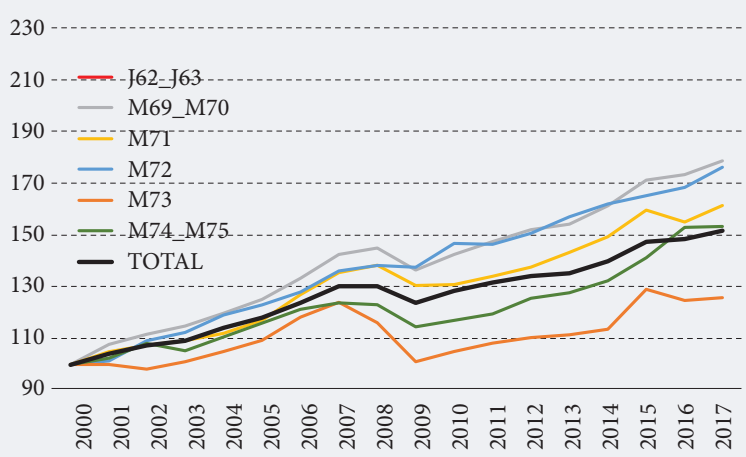

Notes: The sectors featured are: J62_J63 - Computer programming, consultancy, and information service activities; M69_M70 - Legal and accounting activities; activities of head offices; management consultancy activities; M71 - Architectural and engineering activities; technical testing and analysis; M72 - Scientific research and development; M73 - Advertising and market research; M74_M75 - Other professional, scientific and technical activities; veterinary activities. TOTAL refers to the whole economy.

Sources of data: Calculated from Eurostat

grew somewhat less than the total economy. In terms of output, R\&D services show little sign of being impacted by the crisis. Other KIBS demonstrated a sharp downturn. Computer and information services display remarkably high growth and most KIBS remain above the economy as a whole. Broadly speaking, the patterns of KIBS growth in the EU-15 before the crisis have resumed after a brief hiatus. Arguably, A\&E services display a slightly lowered pace of growth in employment and output terms after the crisis than before. ${ }^{1}$ Details vary across different KIBS and countries but overall the experience of the GR suggests that these industries are, in large part, relatively resilient to an economic crisis.

Quantitatively, the coronacrisis's impacts upon GNP and employment look to be both more severe and of longer duration than the GR [OECD, 2020]. The coronacrisis also differs qualitatively from the 2007 2008 crisis, though in both cases service industries, traditionally seen as relatively less impacted by economic crises than other sectors, were badly hit. In the GR, financial services were at the center of the storm. In the coronacrisis, entertainment and hospitality services have sustained heavy losses.

\section{The Coronacrisis}

KIBS are affected - both directly themselves and indirectly through the problems that their clients face and bring to them - by three aspects of the Coronacrisis:

A. The pandemic itself: as it evolves, the patterns of illness and deaths arise. There may be temporary or permanent loss of colleagues, clients, and business partners leading to the loss of knowledge and a disruption of operations. Health and Social Care (HSC) services are impacted acutely, not only by the intermittent availability of human resources. Urgent needs arise for biomedical knowledge and services: shortages of equipment and materials are experienced as demand surges and supply chains falter.
B. The policy responses to the pandemic: efforts are made to understand and apply public policy instruments to "managing" the pandemic, for example by limiting the spread of the virus and by mobilizing health services and related institutions to treat sufferers. Table 1 outlines the main policy responses seen across advanced economies. These responses include identifying and isolating infected individuals, reducing social contacts that can allow pathogens to be transmitted, increasing standards of hygiene, safeguarding the vulnerable people with protective equipment, or other means, introducing large-scale test/track/trace systems, and so on.

C. The persistent impacts of the pandemic and the aforementioned policy responses on the wider economy together with further policy measures designed to offset the most negative impacts and, in some cases, promote new directions for social and economic development. Many businesses are liable to collapse or substantially reduce operations in the wake of the loss of income. Many will need to re-establish customer relationships and build new partnerships and supply chains while patterns of consumer demand are liable to change and business practices could be redesigned to allow for resilience in the face of future pandemics. Persistent impacts of similar sorts may be felt by KIBS themselves, of course - not least in their ability to engage in F2F (face-to-face) interactions with clients.

Figure 3 illustrates these three elements, from both the supply and demand side of KIBS. We shall first consider these elements in terms of how they affect the operations of KIBS and then examine how they impact demand from clients for the services provided by KIBS firms. As we note, considerable uncertainties surround the evolution of the pandemic itself (point A) and one result is uncertainty concerning the application of policy measures (point B). This means that the extent to which various restrictions may remain in place (inter- 
mittently or otherwise) and the duration of this uncertainty is equally uncertain. The ongoing impacts of the coronacrisis on KIBS and other businesses itself could be more or less profound, and more or less extensive over time.

\section{Demand for KIBS}

One immediate impact of the coronacrisis is the reduction or even cessation of activity and income in many sectors. In many countries, several service industries that face difficulties in restructuring in the wake of the introduction of social distancing measures were forced to close or limit operations for extended periods- this often applied to hotels, restaurants, bars and clubs, and much of the retail and consumer services sector along with many cultural, recreational, and entertainment facilities. When "lockdowns" were instituted, the operations of construction, social services, swathes of Agriculture, Forestry and Fishing, and much manufacturing, were substantially curtailed. Much work in these primary and secondary sectors requires physical proximity between co-workers in farms, fisheries, factories, construction sites, and so on. Dramatic decreases in demand were experienced by many public transport sectors as both work and leisure travel diminished. ${ }^{2}$ Contemporarily, the growth of online retail meant increased demand for delivery services and shifts in retail consumption, so the enterprises that shifted to new forms of commerce in a timely manner suffered less.

Other service industries are often less dependent upon particular locations and facilities; professional and administrative work can often be conducted in so- cially distanced ways, notably by working from home (WFH) supported by telecommunications infrastructure [Eurofound, 2020]. WFH (and other forms of remote working, together known as "teleworking" or "telecommuting") was forecast to become prominent by commentators from at least the 1980s [Qvortup, 1998], but developed much more slowly than projected - until taking off dramatically during the coronacrisis [Eurofound, 2020]. The rapid transition to large-scale WFH has proven a major challenge for those industries for whom this was a feasible way of maintaining their business activity - especially given that some of these industries are experiencing substantial changes in demand. However, there are many accounts of businesses deciding that WFH is quite effective and that they can save money currently consumed by expensive office facilities [Dimensional Research, 2020]. This may have substantial long-term impacts on city centers and the businesses serving them.

\section{Financial and Related Problems}

Due to the coronacrisis, many firms are likely to go out of business or pare down activities and discretionary expenditures (including on those KIBS inputs that are not deemed essential in the short-term). A survey of independent consultants found them experiencing drops in contracting for many of their services, with financial consultancy least affected and market research most impacted. ${ }^{3}$ It may well also lead to more caution in the use of KIBS, with clients opting for familiar suppliers, well-known KIBS brands, which will typically mean the larger firms, or in some cases those firms with a strong local presence. This could also imply an avoidance of

\begin{tabular}{|c|c|}
\hline Aim & Contents \\
\hline $\begin{array}{l}\text { Limiting the spread } \\
\text { of the virus and } \\
\text { protecting those most } \\
\text { vulnerable }\end{array}$ & $\begin{array}{l}\text { - Advice, or enforcement of measures, that restrict the use of meeting places such as clubs, bars, restaurants, } \\
\text { hotels, and non-essential shopping venues and public facilities such as libraries, museums, schools and } \\
\text { colleges. This has obvious impacts on the conduct of many businesses, as well as on all levels of education. } \\
\text { - More or less stringent enforcement of what became known as social distancing, requiring people to stay at } \\
\text { home and businesses to shift work online, as far as possible; restricting travel to work for employees in non- } \\
\text { essential industries. Again, many businesses are affected, including KIBS. } \\
\text { - Restricting international movements, seeking to quarantine those arriving from other countries. } \\
\text { - Recommending or enforcing the use of masks (especially in indoor public locations). } \\
\text { - Introduction of testing systems, to identify cases, and tracking systems to locate contacts of those believed } \\
\text { to be infected. }\end{array}$ \\
\hline $\begin{array}{l}\text { Strengthening and } \\
\text { supporting frontline } \\
\text { health and social care } \\
\text { services }\end{array}$ & $\begin{array}{l}\text { - Preventing available HSC resources from being overwhelmed by COVID-19. This includes building/ } \\
\text { redesigning of hospitals and efforts to develop and supply relevant equipment and medicines, and the } \\
\text { provision of support for R\&D that can feed into such efforts to support the capabilities of HSC services to } \\
\text { cope with the pandemic. } \\
\text { Management of complex new procedures established to assist HSC in addressing the coronacrisis, and } \\
\text { KIBS may have roles to play both in providing advice as to organizations and supporting this through the } \\
\text { provision of staff. } \\
\text { - As it becomes evident that COVID-19 can have long-term impacts upon physical and mental health, } \\
\text { increased effort into establishing systems for helping to alleviate these effects is being demanded. }\end{array}$ \\
\hline $\begin{array}{l}\text { Supporting businesses, } \\
\text { employees, and } \\
\text { others affected by the } \\
\text { pandemic and policy } \\
\text { responses }\end{array}$ & $\begin{array}{l}\text { - Impacts related to loss of business due to social distancing and, especially, enforced closure may be } \\
\text { alleviated by various means such as loans, grants, etc. } \\
\text { - Employees may be supported via, for example, furlough schemes (which aim to protect jobs), one-off } \\
\text { payments, or welfare benefit systems. } \\
\text { More general requirements for compensatory measures to offset the loss of time in education and mental } \\
\text { health and similar services to help deal with the emotional fall-out from the coronacrisis are liable to be } \\
\text { significant elements of the long-term policy response. }\end{array}$ \\
\hline
\end{tabular}

\footnotetext{
https://www.itf-oecd.org/transport-face-pandemic (accessed 24.12.2020).

The study was reported on 15 July 2020. Available at https://www.consultancy.uk/news/25094/covid-19s-impact-on-the-independent-consulting-market, accessed 24.12.2020. Over a thousand independent consultants in major countries (UK, US, France, Germany) had been surveyed; large decreases in business came from travel and leisure and the construction sectors, while lower decreases were reported from clients in pharmaceuticals, healthcare, chemicals, and agriculture.
} 


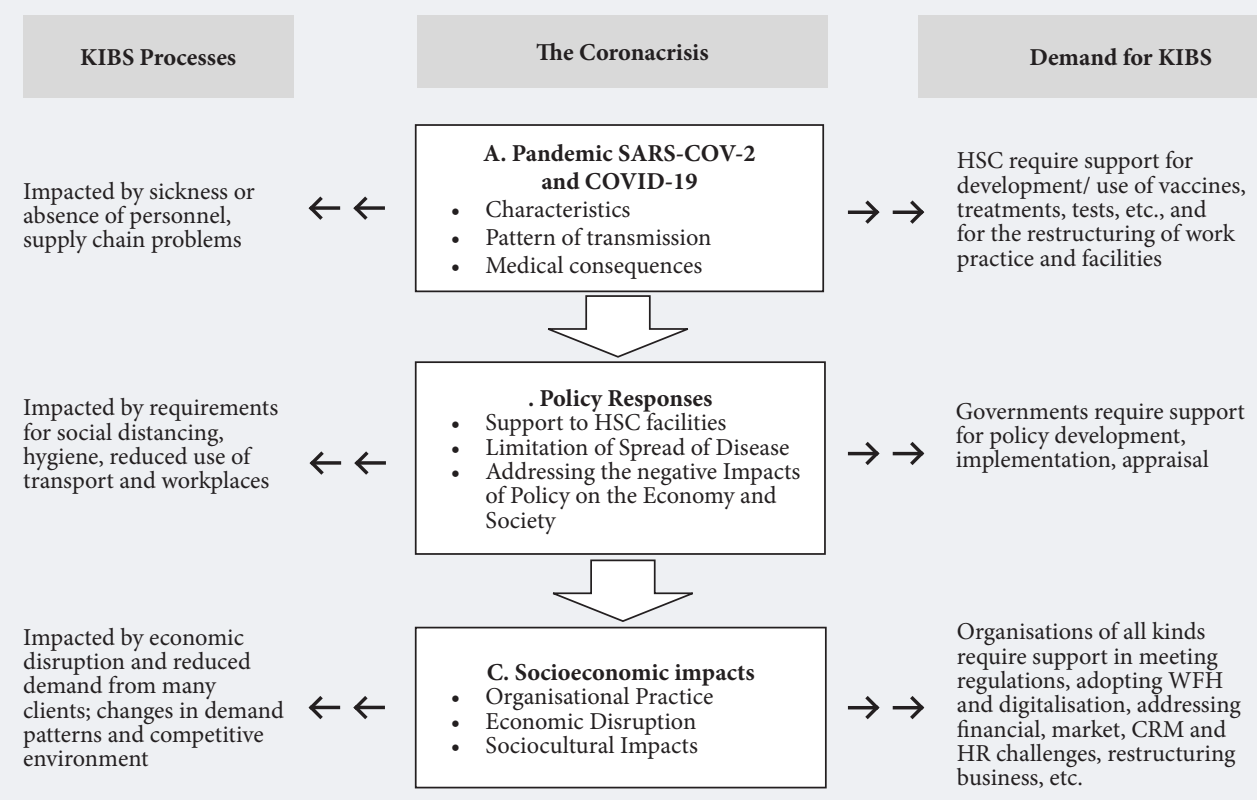

Source: authors.

the risks associated with investing in more novel inputs. Clients will also seek to tackle their problems with internal resources and seek free advice.

Businesses will require assistance in dealing with the fallout from long-term market disruptions. This immediately means demand for support concerning bankruptcy, divestment, property sales, managing redundancy, and a host of related (and often tragic) problems from KIBS, finance and insurance firms, regulatory authorities, and industry associations. Many KIBS have been making free basic advice available, for instance through webpages and webinars, partly to help stave off a huge number of queries from desperate clients, partly to be good citizens supporting their business partners and ecosystems, and as a way of securing the loyalty of existing clients and recruiting custom for more customized and/or elaborate services. Specialized anti-coronacrisis solutions are also widely available from non-KIBS organizations such as charities, universities and business schools, and national and local government agencies, as well as from online communities (Figure 4).

KIBS use may be encouraged by governments, who may facilitate businesses' access to emergency support. A UK example, Recovery Advice for Business, offers free telephone-based advice to small and mediumsized businesses. Topics include accounting, advertising, HR, and legal affairs. Professional bodies and trade associations mobilized experts in their sectors to provide such free advice. ${ }^{4}$ Financial support - such as various types of loans and grants of various types, including those associated with furlough schemes - has been provided to firms by some governments. Such resources are distributed with some safeguards aimed at ensuring that businesses will ensure adequate business plans, commitments concerning staff retention and operating conditions, and so on. KIBS providing accountancy and similar support are liable to confront demand from clients seeking to access such funds, as well as from those providing the funds. ${ }^{5}$

\section{Pandemic Preparedness}

It is far from clear how long the difficulties associated with the pandemic will persist; scenarios on this topic have proliferated. Though several vaccines have been developed rapidly and should be produced on sufficient scale to immunize much of the world's population within a few years, SARS COV2 appears able to mutate readily and may well reinfect people with immunity to earlier strains (as winter influenza and the common cold do). Other zoonotic infectious diseases are likely to emerge, with the intrusion of population growth and modern ways of life into natural environments. Thus, at least some the measures introduced to manage the pandemic may be applied continually, at least in some regions of the world. Even after substantial recurrences of COVID-19 are eliminated (if they are), some distancing and hygiene measures will probably remain in effect for a long time. Such measures may be instituted re-

\footnotetext{
Cf. https://www.enterprisenation.com/freesupport/ (accessed 24.12.2020) and the Northern Ireland-focused https://www.nibusinessinfo.co.uk/content/ coronavirus-business-support-organisations-offering-advice-and-guidance (accessed 24.12.2020).

In a report entitled "Consultants hired to check Covid-19 rescue loans for fraud" (Available at https://www.consultancy.uk/news/25448/consultants-hiredto-check-covid-19-rescue-loans-for-fraud, accessed 24.12.2020), journalists reported that the state-owned British Business Bank was spending more than $£ 1$ million contracting auditors to detect cases of fraud in the distribution of coronacrisis rescue loans, as well as $£ 20$ million in fees to assist in setting up schemes such as Coronavirus Business Interruption, and Bounce Back, Loans.
} 
Figure 4. New Speciality Services in the Wake of the Coronacrisis

Services may be offered to provide support with:

- Accounting

- Accreditation

- Auditing

- Business Continuity

- Customer Service

- Evaluation

- Event Planning

- Facilities Design

- Litigation

- Logistics management

- Marketing and PR

- Opinion and attitudes

research

- Resilience and

Recovery

- Service blueprinting

and design

- Software/web service

design

- Training

Etc.

Source: compiled by the authors.

currently or on a longer-term basis. Businesses will be under pressure from governments, insurers, investors, business partners, employees, and/or consumers to have plans in place for rapid response to future threats. Even if SARS COV2 can be more or less controlled, the world is liable to confront future threats, associated with other emerging diseases, or more virulent varieties of familiar diseases. As policymakers, insurers, business leaders, and informed societies recognize these risks, improved capabilities to respond rapidly to outbreaks by introducing such measures are a likely consequence. Organizations of all sorts will similarly be under pressure to establish plans for ensuring continuity and survival should such measures come into play. This is liable to mean increased demand for risk management and business continuity services are among the KIBS that are active here. Advice may be provided concerning compliance with regulations; plans and designs may be drawn up to render establishments, events, buildings, and working arrangements more pandemic-proof, and to allow organizations to better manage social distancing measures in their internal operations, in interacting and communicating with customers, and so on. Some KIBS are specialists at providing early warnings of ominous developments and emerging risks (a field in which the insurance industry has long had an interest), but they are probably most effective when complementing and feeding into businesses' own systems for monitoring changes in their operating environments. ${ }^{6}$

Some KIBS professions, such as architecture, may need to substantially revise aspects of their curricula and practices to facilitate the use of appropriate design principles. Standardized advice and simple design rules may be sufficient where the issues are mainly about personal behavior (maintaining physical distance, hygiene, face-masking, rules about queuing, etc.) or the use of facilities (discouraging of hot-desking and shared utensils, regular cleaning of surfaces and keyboards, tighter control of cafes, etc.). Where working, transport, or other arrangements require much more restructuring, which may often be the case in, for example, factories, construction sites, and warehouses, more sophisticated designs may be required - probably stimulating the need for engineering and industrial design services, along with those parts of management consultancy focused on work organization, employee relations, and customer relationships.

\section{Suppliers, Customers, and Employees}

Further new demands are liable to arise from businesses associated with disruptions in supply chains - and international tensions were already rendering some established supply chain arrangements and trading patterns problematic. The difficulties occasioned by reliance upon long-distance travel and transport, and on overseas sourcing of what proved to be critical products, are liable to lead to a rethinking of global activities. 9/11 was widely seen as likely to reduce trends towards global just-in-time systems [Sheffi, 2001], but the current crisis is liable to produce much more fundamental changes. Services supporting international businesses may be hit by disruptions to international trade and a possible retraction of some transnational businesses from their global markets. But businesses confronting new patterns of international trade, possibly involving new value chains and lead markets, will require assistance from consultancy and marketing services, among others. The same is true for efforts to support national and regional economies - for example policies and demand for more locally-based production facilities - which may reflect aims of self-reliance for strategic goods and services, but also efforts to create employment opportunities, regional rebalancing, or more social objectives such as providing meaningful work in an era of high automation. Across all sectors, customers, clients, business partners, and other stakeholders are liable to require information as to what the disruption to services and supply chains is liable to mean, what their options are, what the other parties are liable to do. Strategy consultancy of various kinds is liable to encounter clients searching for solutions to both immediate and long-term dilemmas. Often these will involve more use of digital media (thus digital advertising has grown, even if advertising revenues in broadcast TV and print newspapers have declined).

Employees (and other stakeholders) may respond negatively to organizational failures to effect sufficient improvements in terms of social distancing, hygiene, and pandemic preparedness; or conversely, may resist

Risk management has its own ISO standard: ISO 31000 (more details and links to risk assessment techniques are available at: https://www.iso.org/iso31000-risk-management.html, accessed 24.12.2020). Overviews of the field include [Power, 2007; Spedding, Rose, 2007; Andersen, Schroder, 2010]. On success factors for risk management systems, see [Yaraghi, Langhe, 2011]. A discussion of risk and foresight in connection with vaccine development and deployment is presented in [Ozdemir et al., 2011], while [Suk et al., 2008] describe how risk analysis was undertaken in a foresight exercise on infectious diseases. 
changes that render work environments less comfortable, ergonomic, or convivial. Methods to support the psychological resilience of employees can be critical, such as internal counseling services and support groups, team-building and consultation activities, regular demonstration of management's attentiveness to staff concerns and welfare, and leadership that evidences empathy and supportiveness [Kock et al., 2018]. Again, specialist KIBS provide advice in many of these areas.

\section{Technology and Innovation}

Though we have focused upon the damage inflicted by the coronacrisis, some businesses have been unaffected or even benefitted from the pandemic. Suppliers of medical equipment, sanitary products, and pharmaceuticals experienced high demand, along with suppliers of equipment and services supporting online communications and online services of many sorts - among them, retail, entertainment, and news services. The pandemic also accelerated the development of service robots for hospitals, office buildings, and other facilities. KIBS are frequently involved in R\&D on artificial intelligence, navigation systems, robot controls, and user interfaces. Organizations experiencing increased demand often encounter new problems and may require KIBS support to manage expansion, develop strategies, work in new markets, locate and integrate new partners, staff, and technologies. IT consultancies will experience requests from clients as to the issues involved in digitalization. All organizations are being advised to instruct and train staff to avoid cybercriminals exploiting opportunities associated with the pandemic (not least, those associated with remote working).

More generally, however, the financial constraints on businesses are liable to create pressures on funding for innovation. ${ }^{7}$ IT-related efforts have likely been diverted toward the sorts of digitalization that support WFH and customer relations. Longer-term and more ambitious efforts to introduce advanced systems using data analytics, AI, and other applications of new technology and associated approaches have had to be reduced and/or delayed. This will have had knock-on effects on those KIBS involved in advising on, designing, and implementing such systems, while there will be a redistribution of activities within the computer and IT services sector, toward more immediate support and away from the longer-term projects.

This may be reversed once new digital technologies have bedded in. As their use becomes more widespread and routine, so a learning process can be anticipated, much along the lines of Barras' "reverse product cycle" [Barras, 1986, 1990], with users discovering new ways of organizing work, business processes, and customer relationships, and developing new service offerings. There may then be increased interest in the more ambitious, and longer-term, IT-based innovations and this should be associated with a corresponding revival in demand for KIBS support.

\section{KIBS Practice and the Coronacrisis Overall Demand for KIBS}

The discussion above drew attention to some areas where demand for services may grow, but the coronacrisis meant an immediate, substantial drop in the demand for many KIBS. Recent statistics on production and employment dynamics vividly illustrate this (Figures 5 and 6). All industries experienced sudden shocks and it is striking that computer and information services did not appear immune to this. Advertising, which had been impacted badly by the Great Recession, looks to have been particularly badly hit after it had just shown signs of steady growth. The coronacrisis led to many KIBS facing sharp decreases in demand for their services. Sometimes there is the evident postponement of requests, for example, legal services have had to put cases on hold and worry that a mounting backlog of business law cases will eventually need addressing. It is unclear what the consequences will be for the future of KIBS in structural terms - will we see numerous mergers and acquisitions? Will it be larger or smaller companies that are most able to save costs in the ways discussed above? Will there be a growth in KIBS microbusinesses as displaced employees set up their own firms?

\section{Changing Patterns of Demand}

The earlier discussion of the impacts of the coronacrisis upon businesses provided some indications of which sectors are liable to be most affected and of the implications for demand for various KIBS inputs. Relative growth for services that support processes of digitalization, business continuity, and recovery - and dealing with business failure - is a predictable outcome, though such support can be delivered by organizations other than KIBS. Specialized KIBS provide consultancy, legal, and other forms of support for firms facing problems associated with the disruption of global supply chains [Guan et al., 2020]. KIBS themselves may confront problems when they operate internationally, needing to forge new partnerships - some international operations are conducted through franchises, while joint ventures and strategic alliances are among the other common models of partnership [Greenwood et al., 2020]. KIBS play roles in many global supply chains and these roles may well be impacted by the coronacrisis and its fallout. International trade tensions were already growing. These may render the use of overseas KIBS more difficult in some countries and supply chains.

Another aspect of demand change that predates the coronacrisis, but that it potentially accelerates, is the transition to more environmentally sustainable trajectories of economic development. Already some countries and intergovernmental organizations had been drawing up plans for "green growth", the decarbonization of their economies, and similar initiatives [Capasso et al., 2019]. Early in 2020, the need for change was being underlined by Arctic warming, forest fires, and other striking weather-related events. The coronacrisis itself may have 
Figure 5. Volume Index $(\mathbf{2 0 1 5}=\mathbf{1 0 0})$ of production in services in EU (27 countries as in 2020)

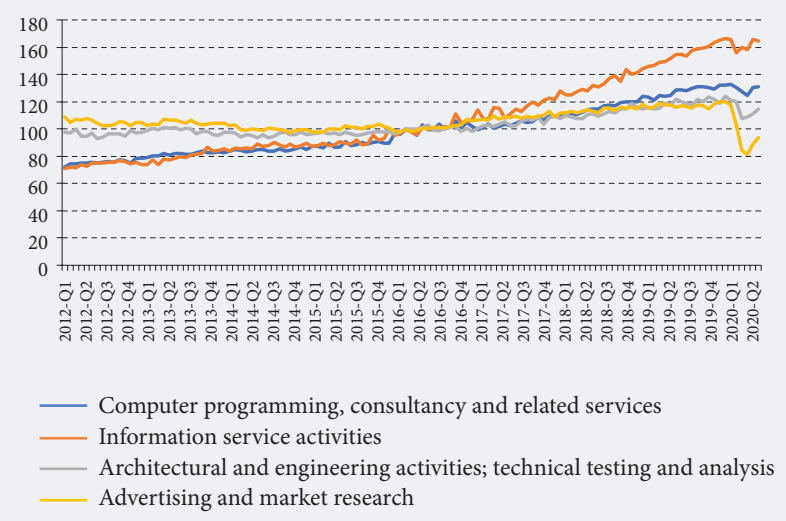

Note: Seasonally and calendar adjusted data

Source: Calculated based on Eurostat data
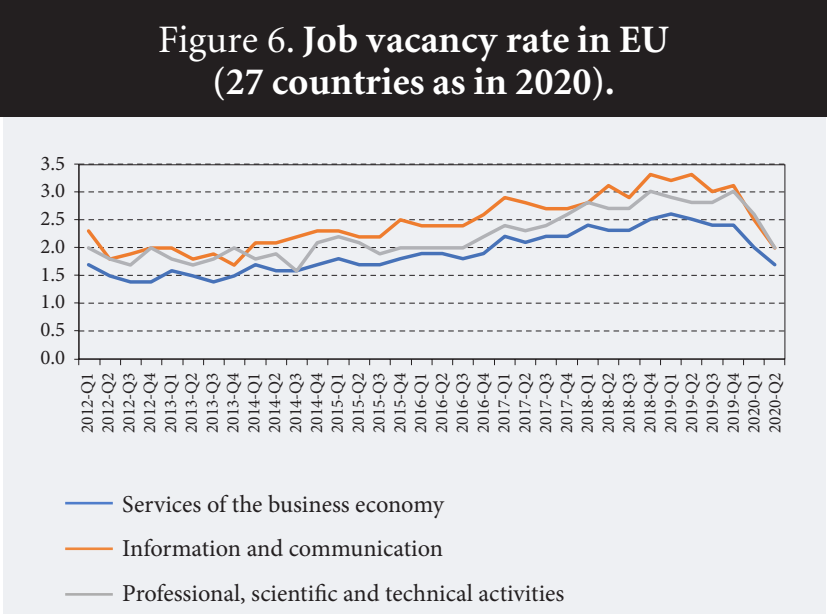

Note: The job vacancy rate (JVR) is the number of job vacancies expressed as a percentage of the sum of the number of occupied posts and the number of job vacancies. Unadjusted data.

Source: Calculated based on Eurostat data. reshaped public perceptions as to the desirability and feasibility of such a transition. The first impact relates to the dramatic demonstration, in many parts of the world, that governments are capable of responding to a crisis with substantial interventions into social and economic affairs. Awareness that such interventions can be politically feasible is claimed to have undermined the belief that the sorts of change required by the global climate crisis are utopian and impracticable.

The second impact relates to public sentiments, as people report greater awareness of the value of nature, of less air pollution, and of reduced pressures to consume and commute. A cross-national survey in 16 major countries (June 2020) found around three-quarters of people expect their government to make protection of the environment a priority in planning recovery from the coronacrisis, and report feeling "a strong responsibility to ensure their generation does not destroy the planet for the next generation" (agreement with this sentiment is close to or over $80 \%$ in all of the countries"). ${ }^{8}$

Thus, we anticipate that despite the hardships induced by the coronacrisis, there will be significant efforts to establish new trajectories of change that create meaningful work and support more sustainable "green growth". For example, policies providing financial support to badly hit industries may tie such support to clear and verifiable undertakings about the substantial and continued reduction of wasteful and polluting activities. Incentives may direct R\&D and innovation efforts toward greener technologies and the restoration of vital ecosystems. KIBS will find new roles in supporting these reorientations of business and innovative efforts [Hartshorn, Wheeler, 2002]. Indeed, numerous KIBS already do specialize in such areas - "green" marketing, design, $\mathrm{R} \& \mathrm{D}$, and similar services.

Another way in which clients' demand may change was also mentioned - expectations that in times of stress many clients will be risk-averse and orient themselves toward more familiar and trusted KIBS. Some commentators see the current crisis as liable to be most severe for smaller KIBS firms, as they are for smaller firms in many sectors. Many small KIBS lack the established brands and reputations and long-term client relationships of larger firms - and may also struggle more with digitalization on account of less efficient IT systems and experience with digital ways of working. Of course, there are some smaller KIBS who are extremely proficient in these aspects, some being technology pioneers, some having extremely strong locality-based linkages.

\section{KIBS Working Practices}

In terms of disruptions associated with the pandemic, such as the absence of members of staff due to illness or social isolation, KIBS resemble other organizations with high proportions of skilled staff. While routine workers may be relatively easy to replace or substitute, the absence of the sorts of professionals employed by KIBS can create severe problems, since they may have unique knowledge, skills, and relationships with clients. This is liable to affect smaller firms most severely.

Nevertheless, many KIBS have had to lay off staff to survive the sharp reductions in revenue they experience though others have sought to retain staff with reduced working hours and some efforts to reduce salaries, benefits, and/or pensions. Where there is little requirement for complex equipment and information systems, many displaced workers may well seek to set up as self-employed service providers. While studies of the current situation have yet to emerge, earlier research indicates that more highly educated and skilled individuals are more likely to become self-employed, though details vary considerably across countries [Dawson et al., 2009; Hatfield, 2015].

\footnotetext{
${ }^{8}$ Available at: https://www.ipsos.com/ipsos-mori/en-uk/majority-people-expect-government-make-environment-priority-post-covid-19-recovery, accessed 24.12.2020.
} 
The policy measures designed to battle the pandemic restrictions on travel, requirements for social distancing, etc. - affect KIBS substantially in terms of communication. In some cases, the meetings with current clients and project partners, authorities, or public parties might well be accomplished digitally; while for much fieldwork it could be more problematic [Poom et al., 2017]. Like other organizations, many KIBS shifted much of their activity to enable employees' WFH. ${ }^{9}$ As stricter lockdown measures relax, KIBS, like other organizations, have to make decisions concerning whether/when/how to return to office-based activities. In many cases, this will not be a simple return to long-established practices. When office-based work is resumed - which may ultimately be on a smaller scale than heretofore - the issues of design of premises and work processes confronted by KIBS will resemble those of other service industries. Some KIBS' technical activities involve tools and equipment that cannot be readily moved away from company premises, normally requiring employees to work on the premises, and in physical proximity with each other. Thus, many engineering, $\mathrm{R} \& \mathrm{D}$, biomedical, and industrial testing services will require a redesign of work processes and restructuring of facilities to reduce the physical closeness of individuals, the introduction of ultra-hygienic practices, and where economically feasible, the use of robotics.

Remote working was already becoming fairly common as an occasional practice before the coronacrisis. In Canadian KIBS, about 20\% of workers in 2016 usually worked most of their time at home compared to $4.7 \%$ in education and $1.6 \%$ in public administration. Moreover, there is quite a strong trend for the share of such workers to increase - from 1996 to 2006 from $15.1 \%$ to $19.0 \%$, respectively. The share of KIBS workers attending the "usual" workplace decreased from $75.5 \%$ in 1996 to $72.0 \%$ in 2006 and $70.7 \%$ in 2016. In addition, 1.6\% of KIBS workers in 2016 worked from abroad [Shearmur, 2020]. In the EU-27, the top two sectors for teleworking by 2018 were IT and communications services followed by other KIBS, education, and publishing/broadcasting. Over $30 \%$ of their workforce "usually or sometimes" teleworked [Sostero et al., 2020]. The picture is somewhat affected by whether we are looking at self-employed people versus employees. The figure for IT and other communication services (and also education) is dominated by employees, while for other KIBS it is much more balanced between selfemployed people and employees. The overall figures of the share of employees involved regularly or with some frequency in WFH were: $35 \%$ of employees in IT and other communication services; $32 \%$ in education; $25 \%$ in publishing activities; and $26 \%$ in other KIBS. The prevalence of telework varies tremendously around the EU, of course, with Northern Europe being most intensive users.

Larger firms are more prone to adopting teleworking than SMEs - though we might expect the self-employed/microbusinesses to deviate from this pattern. Estimating the proportion of workers in various occupations and sectors whose work could effectively be conducted via WFH, Sostero et al. conclude that this will be the case for over two-thirds of Europe's KIBS workers [Sostero et al., 2020]. But this estimate is based mainly on physical handling tasks. Some social interactions are also problematic without F2F contact, and we can now cite occupational data (from April 2020) on who had begun to telework during the early months of the pandemic in Europe. Managerial and professional workers were most likely to do so (more than 50\%) followed by associate professionals and clerical workers (around 40\%). ${ }^{10}$ Many KIBS have relocated work from offices to their employees' homes, supported by the use of computers and communications, Virtual Private Networks, and databases as well as videoconferencing and webinars.

Along with other businesses, KIBS may have been reluctant to fully embrace remote working because of perceived risks - cybersecurity threats (leakage of confidential information, hacking into corporate systems); lack of efficiency among employees; problems with teamwork; and so on. But as they learn about the scope of these systems and where there are benefits, we would anticipate motivation for ongoing change in KIBS firms' internal organization and interactions with clients. In particular, it can be anticipated that the savings of expenses and effort associated with office rents and maintenance costs, and high levels of travel, will dampen enthusiasm for a reversion to traditional practices. We may also anticipate a "reverse product cycle"type process, as discussed for businesses in general, in which new services are introduced to take advantage of the new capabilities that have been acquired.

Office expenses are substantial for KIBS. While about half of the total costs of Russian KIBS in 2015 involved personnel, the second largest source of expenses was on offices and related services (utilities, etc.). These constituted about $16 \%$ of the total expenditures in Russian KIBS ranging from less than $14 \%$ for web and digital services to $18 \%$ for marketing and related services. Smaller shares were allocated for equipment, advertising, and other items [Belousova, Chichkanov, 2016]. This is why accountants frequently target offices as the first item of fixed overhead costs to reduce when making savings. Some companies prefer to forward the released funds to personnel development.

Learning about extending digital working practices has meant, for many KIBS firms, acquiring a deeper understanding of cybersecurity problems and solutions to mitigate the risks resulting from "work anywhere" operating models. Cloud computing reduces the need for localized physical storage, providing on-demand files and data, but also requires enhanced security. Likewise, experience has been gained of business, project management, and performance management solutions that can be applied to assigning ongoing business tasks (from accounting to HR) with adequate time management and delegation of duties. Communication among employees needs to find new platforms that can help maintain motivation and enable the sharing of ideas.

However, the fact that some elements of KIBS can be more or less effectively handled digitally does not mean

\footnotetext{
For data on the shift to teleworking across Europe see [Eurofound, 2020; Sostero et al., 2020].

${ }^{10} \mathrm{https} / /$ www.consulting.us/news/3966/four-ways-to-embrace-remote-work-during-covid-19-crisis, access date 24.12.2021.
} 
that we should anticipate a comprehensive and longlasting transition to these approaches. Many KIBS have traditionally relied on substantial face-to-face (F2F) exchanges with clients. More routine and standardized KIBS - preparing accounts and basic legal briefs for small firms, tailoring standard databases and web designs for such clients, for example - may be effectively conducted online. These are the service activities that have already often been offshored.

KIBS produce their services through a set of steps, often organized into projects, from initial problem definition to solution provision (and beyond, sometimes, to the evaluation of the success of the service - for example, advertising companies may research the impact of the campaigns they have mounted) (see Figure 7). Interactions between KIBS and clients are most intense in the earlier and later stages of the service process [Lehrer et al., 2012]. Interaction is needed to establish mutual agreements as to the nature of the client's business problem, the resourcing and type of solution possible, the specifics of the defined solution, the implementation of the solution, and the evaluation of its outcomes. It often involves the exchange of documents, but also typically requires substantial F2F contact at particular moments in the service process. The main exceptions are where the service is a fairly routine and standardized one, such as accountancy and audit for small businesses, repetitive types of technical testing, and such legal services as drawing up standard contracts.

In some cases, there can be more F2F contact with third parties than with the actual client. For example, market research may involve interactions with members of the public; legal services may require interactions with those in the courts. In addition, "front office" staff are liable to have more client contact than "back office" staff, by definition they are more customer-facing. KIBS representatives who facilitate the exchange of re- sources and knowledge typically rely more on F2F contacts. While those employees who perform more independent tasks like knowledge creation rely more upon technology-enabled communication - as, in contrast, do those dedicated to more standard tasks (e.g., creating presentations) [Breidbach, Maglio, 2016].

Much of the activity involved in client relations and teamwork can be largely conducted using online communications and databases. Those firms that already had much of their technical knowledge base stored electronically will have found this transition easier to undertake. But such media are limited when it comes to communicating body language cues, facilitating informal interactions (often the site of creative and informative exchanges), and establishing the close relationships that are required for effective KIBS operations. F2F encounters have enabled the alignment of knowledge between individuals through the mutual use of tools such as whiteboards. There are various efforts to replicate such tools in online environments, along with other aids for computer-supported collaboration.

Online communications are rarely designed to support such more informal exchanges even when systems enable break-out groups and private messaging alongside the main discussion. Furthermore, there are real limitations in current electronic communications, even when using high-definition images. KIBS practitioners interviewed by Growe [Growe, 2019] also highlight the critical roles of non-verbal communication and body language for the development of trusting relationships with their clients. Client-facing professionals often need to be aware - especially during the problem-definition phase - of nuances, lacunae, signs of unease or embarrassment, evidence of friction, and/or relations of power among members of the client team. Attention to such signals can be very important in defining the nature of the problem and the types of solutions likely

Figure 7. KIBS-Client Interactions

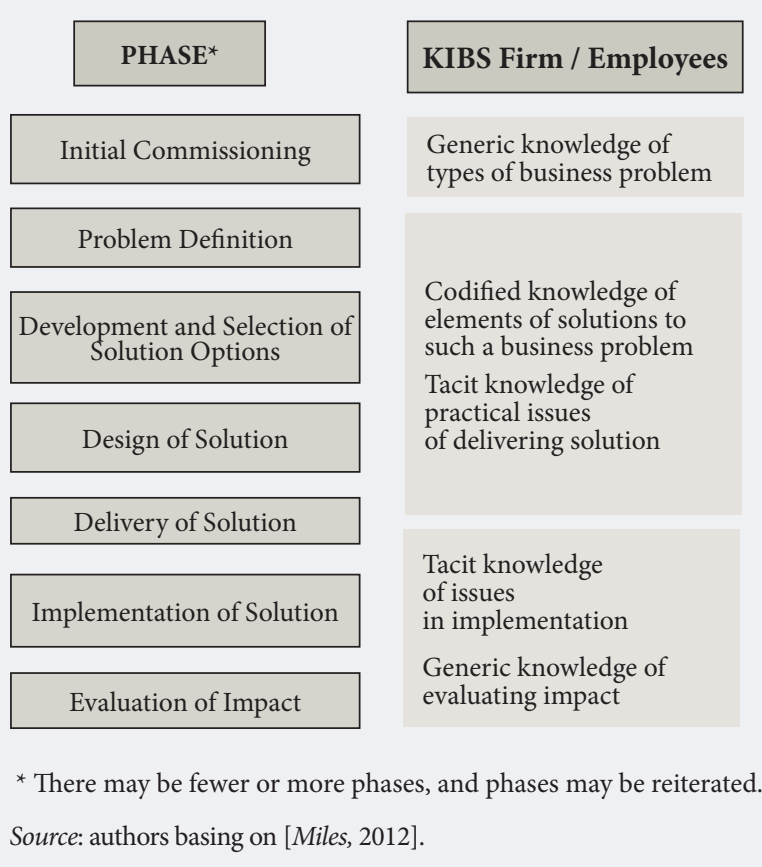

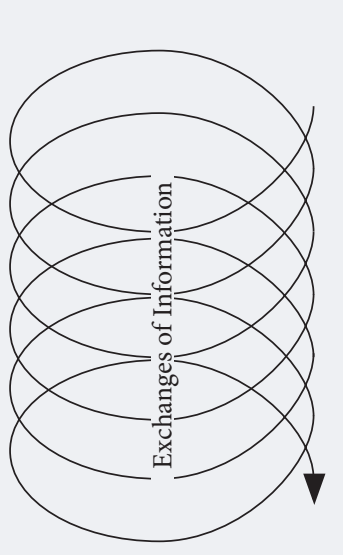

Fusions of generic and local knowledge

\section{Client Firm / Employees}

Generic knowledge of business processes, local knowledge (some tacit) of firm and its environment, and of options for sourcing knowledge inputs from KIBS and elsewhere

Acquisition of deeper knowledge of business problems and potential solutions

Codified and tacit knowledge as to nature and implementation of solution, possibly involving formal training, manuals, etc.

Own evaluation of success of service implementation 
to be effectively implemented by the client. Thus, F2F interactions support knowledge exchange and facilitate the building of trust and "chemistry" between partners, whether team members or clients [Growe, 2019].

Whether F2F interactions remain restricted after the coronacrisis, innovation efforts will likely continue to be aimed at narrowing the gap between F2F and digital interactions. Such developments are liable to be of use to firms other than KIBS, and some have already been pioneered in high-tech industries (and the military). We anticipate the development of:

- Team building procedures that can operate effectively in digital space. Often structured as games of one sort or another, these typically involve little additional technology, but involve guidelines and often require facilitation.

- Tools that provide many of the dialogue-enhancing functions currently associated with whiteboards and flip charts. Their designs may resemble these familiar instruments or take on quite novel forms. As well as enabling collaboration in creating, modifying, and selecting within texts, lists, illustrations, and 3D designs, such tools can enable voting, ranking, and other ways of getting a sense of areas of agreement and contention.

- Virtual Reality (VR), augmented reality, and telepresence systems may allow for a greater sense of mutual presence in the service interactions. VR goggles and headsets allow some degree of the visual experience of a 3D environment in which meetings take place. Currently, the virtual bodies (avatars) that participants don in Second Life-type environments are minimally related to their actual postures and movements, and are presented in flat $2 \mathrm{D}$ displays, though $3 \mathrm{D}$ visualization is becoming affordable. Even in these limited systems, participants can peel off from the main meeting into more secluded environs and use tools to enhance dialogue. The rapid development of videogames and simulations demonstrates the scope for implementing far more realistic, novel and immersive virtual environments [Ekstrom, 2017].

- Haptic systems include devices that enable people to "shake hands", sign documents, work together on and touch not only drawings but also virtual 3D objects (which might then be realized through 3D printers). Abilities to "feel" things and people may be provided by special gloves, for example [Culbertson et al., 2018, Pacchierotti et al., 2017; Sreelakshmi, Subash, 2017].

- New types and ways of applying and verifying digital personae, building on the avatars and agents that are currently in use. Both practice and literature on these topics are growing exponentially and in diverse directions [Aljaroodi et al., 2019].

The sorts of professional systems that allow for telepresence, full-body imaging, and realistic haptic contact are liable to be well out of the price range for many smaller KIBS though innovation in cheaper consumer products may change this. The ongoing development of KIBS' products, as well as their processes, is bound to expand as new ways of working and interacting open up prospects for new services.

\section{KIBS Offerings}

Given their lesser dependence on F2F interchanges, those KIBS producing more routine and standardized services are likely to face less pressure to rapidly adopt the sorts of approaches discussed above. However, any firm is liable to find competitors gaining market share through appearing to be using more up-to-date tools. Pressures to adopt new approaches may be pervasive unless an organization is seeking to stress its adherence to traditional methods.

KIBS who have emphasized highly customized services may seek to shift their offerings to ones that require less F2F contact. One option is akin to "mass customization" - providing a menu of optional modules which the client is encouraged to choose between [Cabigiosu et al., 2015]. Another is a form of "personalization", where a common core of activities is modified only with respect to more client-specific details - the data entered into a tax return or the names, images, and product details on a client's website, for example. Clients may be provided with tools whereby they can personalize the outcome via a form of "self-service", for example, by completing a template or series of questionnaires, whereby an informational service output - a database, a tax return, a web page, etc. - can be generated to specifications. Such increasingly standardized services may be actually preferred by some clients, who may find self-service cheaper and more convenient than direct contact with consultants.

Those KIBS most agile at adapting to new ways of working will be more likely to survive the downturn of demand associated with the coronacrisis. We can anticipate ongoing efforts to ensure that more vital knowledge is electronically available to employees and that they are trained in accessing and applying such resources, though it will also be important to ensure the security of confidential information. As suggested above, over time, a Barras-type "reverse product cycle" phenomenon could be visible - KIBS would learn from their forced rapid digitalization and ultimately be able to create new services based on this learning. It would be wise to draw on the experience of their staff, both as concerns teamworking and project management, as well as experience with customer (and wider network) relationships.

\section{Conclusions: Implications for the Future of KIBS}

The discussion above has outlined a range of prominent impacts and responses, though it can be by no means comprehensive. Further work would be necessary to discuss, for example, the developments in emerging economies (where KIBS are often playing important roles), or such issues as the new patterns of localization of clients and the KIBS servicing them and the likely responses these may evoke from city planners and other policymakers. For example, some established KIBS are liable to consolidate and build upon the innovative services they rapidly introduced, developing speciality offerings in these areas. New specialized entrants are also likely to play a role here, too.

KIBS are liable to face challenges from firms in other sectors. For example, office cleaning, transport, and 
other more operational business service firms are experiencing new constraints and demands, and some of these are offering new services connected with their specialties. We can expect some of these to append related consultancy and management services to their offerings. ${ }^{11}$ Some may move away from operational services altogether to focus on strategy, design, and other management services. Services similar to those offered by KIBS may also be supplied, at least partially, by other parties. For example, government agencies, industry associations, HEIs, and others have been providing advice and support to organizations hit by the coronacrisis. Furthermore, some established KIBS may face new types of "competition" as increasing numbers of potential clients may turn to online resources for help with some of their business problems [Susskind, Susskind, 2015]. Some free resources are provided in the freemium form would be disruptive innovators offering (usually pared-down) alternatives to conventional KIBS. This could well accelerate disruptive trends in areas such as fintech, lawtech, and crowdsourcing initiatives in areas like design and research.

This essay has focused on the impacts of a sudden crisis upon KIBS. The crisis is far from a "black swan" event - epidemiologists and public health bodies have long been warning about the likelihood of a major pandemic. This differs from the more endogenous roots of the Great Depression and Great Recession crises that were much more to do with the relationship between economic and political institutions. KIBS seem to have recovered along with the rest of the global economy after the GR, but the Great Depression persisted until a major war upset lives and livelihoods even more. The coronacrisis has already had deep impacts upon many economies and persistent effects are likely - not least in the social sphere, where many young people find their expectations as to education and careers upturned.

While we have outlined numerous challenges that KIBS are confronting and will continue to face into the foreseeable future, we have also demonstrated that these firms are often extremely active in seeking to help their clients deal with the problems that they too are facing. KIBS play important roles in helping provide solutions to business problems in "normal" times and their role in recovery is very likely to be vital.

However, recovery is unlikely to mean returning to the old "normal". A flock of ominous black swans are approaching in connection with another much-heralded crisis: the climate crisis, again this has much to do with the relationship between our economies and the biosphere. KIBS should be able to play significant roles in the transition of our economies to more environmentally sustainable trajectories of economic development. Organizations of all sorts are liable to confront problems associated with efforts to ameliorate the crisis and avert its worsening. Hopefully we will see the problemsolving capabilities of KIBS brought to bear - sufficient- ly rapidly and extensively - in helping to develop, disseminate, and implement solutions. If not, they could be overwhelmed by demands to deal with a multitude of business problems that will be engendered by further substantial global warming. Policymakers have evident responsibilities to establish incentives and regulatory frameworks that rise to the challenge. Such frameworks would encourage clients to look for greener solutions to their business problems and to define their problems in terms of the growing crisis (and not, for example, as a matter of PR and "greenwashing"). KIBS practices will then focus increasingly on the development, dissemination, and application of knowledge relevant to confronting the climate crisis..

While much specialist work in public health and risk appraisal did engage with the likelihood of future pandemics, this was rarely cited in major foresight exercises. $^{12}$ On reflection, given how the coronacrisis was greeted as a surprise by most commentators, it might be argued that all foresight exercises, on whatever theme, should have carried the warning that sooner or later this risk could considerably disrupt affairs. Beyond specialist work, little attention was paid to the logistical and other challenges a pandemic could engender in health services and across wide swathes of most economies. Pandemic preparedness was insufficient (with the probable exception of a few East Asian countries). Neither foresight and risk appraisal practitioners, nor the public health and epidemiological teams who had led specialist appraisals of pandemic contingencies, had managed to get their concerns taken sufficiently seriously by politicians and policymakers. More effective channels of communication need to be established concerning impending crises and risks, in general. This, of course, is old news for climate change researchers, who have struggled for years to raise the alarm and reshape policy agendas.

Crises involve cascades of problems (and responses), generating further problems (and responses), often with unexpected features. In the coronacrisis, it was not just the disease that displayed such features: the failures of political leadership, public attitudes, bottlenecks in supply chains, and the availability of skilled workers, all came into play. It is necessary to explore multiple scenarios when considering major risks and to not shirk from contemplating some real wild cards. Looking back at the GR, Gordon Brown (then UK prime minister) declared: “...it was not enough just to do day-today crisis management, or even to be one step ahead of events; the real challenge is to anticipate the next problem but one."13 To achieve this, and act upon it, calls for real foresight and leadership.

The article was prepared within the framework of the Basic Research Program at the National Research University Higher School of Economics.

\footnotetext{
${ }^{11}$ Such a process is known as "KIBSification" [Brax et al., 2008], and described without this label in [Djellal, 2002].

${ }^{12}$ One exception is the UK Foresight Programme, which ran a striking projection on "Detection and Identification of Infectious Diseases" (published in 2006, available at https://bityl.co/4uGx; see also [Suk et al., 2008]; the recent Russia 2030 study drew attention to the danger of pandemics and the scope for new approaches to vaccine development [Gokhberg, 2016].

${ }^{13} \mathrm{https} / /$ www.theguardian.com/commentisfree/2020/sep/15/britain-crisis-recovery-coronavirus-gordon-brown, accessed 24.12.2020.
} 


\section{References}

Aljaroodi H.M., Adam M.T. P., Chiong R., Teubner T. (2019) Avatars and Embodied Agents in Experimental Information Systems Research: A Systematic Review and Conceptual Framework. Australasian Journal of Information Systems, 23, 1-37. https://doi.org/10.3127/ajis. v23i0.1841

Andersen T.J., Schroder P.W. (2010) Strategic Risk Management Practice: How to Deal Effectively with Major Corporate Exposures, Cambridge: Cambridge University Press.

Barras R. (1986) Towards a Theory of Innovation in Services. Research Policy, 15(4), 161-173. https://doi.org/10.1016/0048-7333(86)90012-0

Barras R. (1990) Interactive innovation in financial and business services: The vanguard of the service revolution. Research Policy, 19(3), 215-237. https://doi.org/10.1016/0048-7333(90)90037-7

Belousova V., Chichkanov N. (2016) Knowledge-Intensive Business Services in Russia: 2014-2015 Crisis Aftermath. Foresight and STI Governance, 10(4), 46-58. DOI: 10.17323/1995-459X.2016.4.46.58

Brax S., Toivonen M., Smedlund A., Valminen K. (2008) Kibsification of industrial services. Paper presented at the 18th International RESER Conference: New Horizons for the Role and Production of Services, Stuttgart, Germany, 25-26 September 2008. https://bit.ly/2Y7oE6n, accessed 16.12.2020.

Breidbach C.F., Maglio P.P. (2016) Technology-enabled value co-creation: An empirical analysis of actors, resources, and practices. Industrial Marketing Management, 56, 73-85. https://doi.org/10.1016/j.indmarman.2016.03.011

Cabigiosu A., Campagnolo D., Furlan A., Costa G. (2015) Modularity in KIBS: The Case of Third-Party Logistics Service Providers. Industry and Innovation, 22(2), 126-146. https://doi.org/10.1080/13662716.2015.1023012

Capasso M., Hansen T., Heiberg J., Klitkou A., Steen M. (2019) Green growth - A synthesis of scientific findings. Technological Forecasting and Social Change, 146, 390-402. https://doi.org/10.1016/j.techfore.2019.06.013

Culbertson H., Schorr S.B., Okamura A.M. (2018) Haptics: The Present and Future of Artificial Touch Sensation. Annual Review of Control, Robotics, and Autonomous Systems, 1, 385-409. https://dx.doi.org/10.1146/annurev-control-060117-105043

Dawson C.J., Henley A., Latereille P.L. (2009) Why Do Individuals Choose Self-Employment? (IZA Discussion Paper 3974), Bonn: Institute of Labor Economics (IZA). https://ssrn.com/abstract=1336091, accessed 24.12.2020.

Dimensional Research (2020) The Rise of the Hybrid Workplace, San Jose, CA: Dimensional Research. https://bityl.co/4wI8, accessed 24.12.2020.

Djellal F. (2002) Innovation trajectories and employment in the cleaning industry. New Technology, Work and Employment, 17(2), 119-131. https://doi.org/10.1111/1468-005X.00098

Ekstrom M. (2017) Communication tool in virtual reality - A telepresence alternative. An alternative to telepresence-bringing the shared space to a virtual environment in virtual reality (Master Thesis), Sundsvall: Mid Sweden University. https://www.diva-portal.org/smash/get/ diva2:1134805/FULLTEXT01.pdf, accessed 19.10.2020.

Eurofound (2020) Living, working and COVID-19- first findings, Luxembourg: Publications Office of the European Union. https://www. eurofound.europa.eu/sites/default/files/ef_publication/field_ef_document/ef20059en.pdf, accessed 24.12.2020.

Gokhberg L. (ed.) (2016) Russia 2030: Science and Technology Foresight, Moscow: Ministry of Education and Science of the Russian Federation, HSE University (in Russian).

Greenwood R., Morris T., Fairclough S., Boussebaa M. (2010) The organizational design of transnational professional service firms. Organizational Dynamics, 39(2), 173-183. https://doi.org/10.1016/j.orgdyn.2010.01.003

Growe A. (2019) Developing trust in face-to-face interaction of knowledge-intensive business services (KIBS). Regional Studies, 53(5), 720-730. https://doi.org/10.1080/00343404.2018.1473567

Guan D., Wang D., Hallegatte S., Davis S.J., Huo J., Li S., Bai Y., Lei T., Xue Q., Coffman D., Cheng D., Chen P., Liang X., Xu B., Lu X., Wang S., Hubacek K., Gong P. (2020) Global supply-chain effects of COVID-19 control measures. Nature Human Behavior, 4, 577-587. https://doi. org/10.1038/s41562-020-0896-8

Hartshorn J., Wheeler D., (2002) Facilitating Strategic Business Responses to Sustainability Prospects and Challenges for Professional Services Firms. Greener Management International, 40, 107-119. http://www.jstor.org/stable/greemanainte.40.107

Hatfield I. (2015) Self-employment in Europe, London: Institute for Public Policy Research. https://www.ippr.org/files/publications/pdf/selfemployment-Europe_Jan2015.pdf, accessed 24.12.2020.

Kock N., Mayfield M., Mayfield J., Sexton S., De La Garzao L. (2018) Empathic leadership: How leader emotional support and understanding influencesfollowerperformance. JournalofLeadership¿ OrganizationalStudies, 26,217-236.https://doi.org/10.1177\%2F1548051818806290

Lehrer M., Ordanini A., DeFillippi R., Miozzo M. (2012) Challenging the orthodoxy of value co-creation theory: A contingent view of co-production in design-intensive business services. European Management Journal, 30(6), 499-509. https://doi.org/10.1016/j. emj.2012.07.006

Miles I. (2012) KIBS and Knowledge Dynamics in Client-Supplier Interaction. In: Exploring Knowledge-Intensive Business Services: Knowledge Management Strategies (eds. E. Di Maria, R. Grandinetti, B. Di Bernardo), London: Palgrave, 13-34.

OECD (2020) OECD Employment Outlook 2020, Paris: OECD. Available at: https://www.oecd-ilibrary.org/employment/oecd-employmentoutlook-2020_1686c758-en, accessed 24.12.2020.

Pacchierotti C., Sinclair S., Solazzi M., Frisoli A., Hayward V., Prattichizzo D. (2017) Wearable haptic systems for the fingertip and the hand: taxonomy, review, and perspectives. IEEE Transactions on Haptic, 10(4), 580- 600. DOI: 10.1109/TOH.2017.2689006

Poom A., Orru K., Ahas R. (2017) The carbon footprint of business travel in the knowledge-intensive service sector. Transportation Research Part D, 50, 292-304. https://doi.org/10.1016/j.trd.2016.11.014

Power M. (2007) Organized Uncertainty: Designing a World of Risk Management, London: Oxford University Press.

Qvortup L. (1998) From Teleworking to Networking: Definitions and Trends. In: Teleworking: International Perspectives from Telecommuting to Virtual Organisation (eds. P.J. Jackson, J. M. Van der Wielan), London: Routledge, 21-39.

Shearmur R. (2020) Conceptualising and measuring the location of work: Work location as a probability space. Urban Studies (in press, first published online 15.05.2020). https://doi.org/10.1177\%2F0042098020912124.

Sheffi Y. (2001) Supply chain management under the threat of international terrorism. International Journal of Logistics Management, 12(2), 1-11. https://doi.org/10.1108/09574090110806262

Sostero M., Milasi S., Hurley J., Fernández-Macías E., Bisello M. (2020) Teleworkability and the COVID-19 crisis: A new digital divide?, Dublin: Eurofound. https://www.eurofound.europa.eu/sites/default/files/wpef20020.pdf, accessed 24.12.2020.

Spedding L.S., Rose A. (2007) Business risk management handbook: A sustainable approach, Burlington: Elsevier Ltd.

Sreelakshmi M., Subash T.D. (2017) Haptic technology: A comprehensive review on its applications and future prospects. Materials Today: Proceedings, 4(2), 4182-4187. https://doi.org/10.1016/j.matpr.2017.02.120

Suk J.E., Lyal C., Tait J. (2008) Mapping the future dynamics of disease transmission: Risk analysis in the United Kingdom Foresight Programme on the detection and identification of infectious diseases. Eurosurveillance, 13(44), 1-7. DOI: 10.2807/ese.13.44.19021-en

Susskind R., Susskind D. (2015) The Future of the Professions: How Technology will Transform the Work of Human Experts, Oxford: Oxford University Press.

van Dorn A. (2020) COVID-19 and readjusting clinical trials. The Lancet, 396(10250), 523-524. https://doi.org/10.1016/S0140-6736(20)3178

Yaraghi N., Langhe R.G. (2011) Critical success factors for risk management systems. Journal of Risk Research, 14(5), 551-581. https://doi. org/10.1080/13669877.2010.547253 